\title{
Correction to: Youth Transitions among Descendants of Turkish Immigrants in Amsterdam and Strasbourg:
}

\section{Correction to:}

E. Keskiner, Youth Transitions among Descendants of Turkish

Immigrants in Amsterdam and Strasbourg:, IMISCOE

Research Series, https://doi.org/10.1007/978-3-030-11790-0

This book was inadvertently published with incorrect affiliation of the author

"Elif Keskiner". It has now been updated as: Department of Sociology, Vrije Universiteit, Amsterdam, The Netherlands 